\title{
ANÁLISE DO LIVRO DIDÁTICO E DESCOBERTAS DOS SABERES DOCENTES NO PROCESSO DE FORMAÇÃO DE PROFESSORES DE ESPANHOL
}

\author{
Apresentação: Comunicação Oral \\ Bárbara Campos Gines Lorena de Souza ${ }^{1}$; Louise Alane Martins Barbosa ${ }^{2}$; Eulália Raquel \\ Gusmão de Carvalho Neto ${ }^{3}$ e Francisca Carneiro Ventura ${ }^{4}$
}

\section{Resumo}

O presente artigo tem como objetivo discutir a importância da análise do material didático - em particular do livro didático - para o desenvolvimento dos processos de ensino e aprendizagem do Espanhol como Língua Estrangeira. Destaca a importância desse processo para a formação de uma postura crítico-reflexiva de professores de espanhol e parte do pressuposto de que o estágio docente supervisionado é um espaço de estudo e de reflexão crítica da prática docente, sendo considerado como uma etapa importante no processo formativo dos futuros professores. Para atingir o objetivo proposto adota como aporte teórico os estudos feitos por Pimenta (2001), Pimenta e Lima (2004), Barreiro e Gebran (2006), Libâneo (1994), Alarcão (2001), entre outros. Como aporte metodológico recorre à abordagem qualitativa de investigação com foco na pesquisa documental e na pesquisa de campo. Para a pesquisa documental utiliza as publicações elaboradas e disponibilizadas pelo Programa Nacional do Livro Didático (PNLD). Outra fonte de dados foi a coleção de livros didáticos - composta por três volumes - adotada pelo Ensino Médio Integrado do IFRN, campus Natal-Central (CNAT) no ano de 2016. Em relação à pesquisa de campo, foram feitas entrevistas com três professoras de espanhol, colaboradores do estágio docente supervisionado. No que se refere à análise dos dados usa a técnica de análise de conteúdo. Para concluir, infere ser a etapa do estágio teórica-analítica, presente na proposta de estágio docente do IFRN, de extrema relevância para a formação do professor. Tal proposta tem proporcionado ao estagiário o conhecimento do material didático e esse esforço prepara uma série de reflexões relativas ao livro didático e relativas à importância de o professor elaborar o seu próprio material didático, formado pelo conjunto de recursos de que dispõe, associando a teoria com a prática num fazer docente crítico e reflexivo. Por conseguinte, chega à conclusão de que o LD é um elemento de fundamental importância para o desenvolvimento do trabalho docente, no entanto, deve ser percebido como um ponto de referência, não devendo ser encarado como o único material a ser utilizado em

\footnotetext{
${ }^{1}$ Licenciatura em Espanhol no Instituto Federal de Educação, Ciência e Tecnologia do Rio Grande do Norte, E-mail: ginesbarbara@ hotmail.com

${ }^{2}$ Licenciatura em Espanhol no Instituto Federal de Educação, Ciência e Tecnologia do Rio Grande do Norte, E-mail: louisealane @ hotmail.com

${ }^{3}$ Professora Doutora do Instituto Federal de Educação, Ciência e Tecnologia do Rio Grande do Norte. Email: eulalia.gusmao@ifrn.edu.br

${ }^{4}$ Pedagoga do IFRN, mestra em educação pela UFRN e doutoranda em Educação pela Universidade do Minho. E-mail: francisca.ventura@ifrn.edu.br
} 
sala de aula. É fundamental saber que o uso do LD não elimina a possibilidade de novos recursos e sim auxilia na seleção e organização dos objetivos e conteúdos escolares.

Palavras-Chave: Estágio, Formação de professor, Livro didático, Reflexão.

\section{Introdução}

O presente artigo tem como objetivo discutir a importância da análise do material didático - em particular do livro didático - para o desenvolvimento dos processos de ensino e aprendizagem do Espanhol como Língua Estrangeira (ELE) na Educação Básica.

Nosso ponto de partida foi o trabalho realizado durante a segunda etapa do Estágio Docente Supervisionado que faz parte do currículo do Curso Superior de Licenciatura em Letras - Espanhol na modalidade presencial (PPC, 2012), desenvolvido no semestre letivo de 2016.1 e oferecido pelo Instituto Federal de Educação, Ciência e Tecnologia do Rio Grande do Norte, Campus Natal-Central. Durante esse semestre letivo, o grupo de alunos estagiários foi composto por nove alunos e por uma professora coordenadora/orientadora de estágio que denominamos de grupo classe.

O estágio II conta com 100 horas/aula e é realizado no $6^{\circ}$ período do curso. No semestre letivo de 2016.1, referência para este artigo, o plano de atividades a ser desenvolvido pelo estagiário contemplou a fundamentação teórica desenvolvida nos seminários de estágio, a caracterização e observação da escola e da sala de aula objeto da realização do estágio, além da análise do livro didático escolhido e utilizado pelos professores do IFRN-Campus Natal Central como campo do estágio.

Essa última atividade nos chamou atenção por percebermos que dentre os vários elementos mediadores dos processos de ensino e aprendizagem, o livro didático apresenta-se como um dos principais, interferindo diretamente no trabalho pedagógico, já que, muitas vezes, é o único recurso do qual o professor da Educação Básica das escolas públicas estaduais dispõe como auxilio a sua prática docente.

Dessa forma, consideramos de extrema importância esse estudo, pois a partir dele o estudante pode ampliar olhares para discussões de temas transversais que entrecruzam diversas áreas do saber, além de contribuir com a formação de professoresinvestigadores que analisam seus materiais didáticos com reflexão e criticidade.

Diante do exposto, nosso artigo apoia-se em princípios da pedagogia crítica e fundamenta-se nos estudos de Gauthier (1998), Pimenta e Lima (2004), Alarcão (2001), dentre outros. $\mathrm{O}$ aporte metodológico assenta-se na abordagem qualitativa para a análise documental e de campo. O tratamento dos dados consistiu nas análises de conteúdo dos 
livros didáticos e dos dados das entrevistas aplicadas aos professores colaboradores do estágio docente supervisionado.

\title{
Fundamentação Teórica
}

O estágio docente supervisionado faz parte da estrutura curricular do curso Superior de Licenciatura em Letras - Espanhol na modalidade presencial (PPC, 2012), oferecido pelo Instituto Federal de Educação, Ciência e Tecnologia do Rio Grande do Norte, Campus Natal-Central. Sendo assim, requisito da Lei de Diretrizes e Bases da Educação Nacional (LDB), nº 9394/96, que o torna indispensável para a formação do professor, como também, para a conclusão do referido curso. Esse processo possibilita a inserção do aluno da licenciatura no contexto atual da educação, a fim de avaliar a prática pedagógica vivenciada no ambiente escolar.

Segundo BARREIRO e GEBRAN (2006, p. 21):

\begin{abstract}
A formação inicial e o estágio devem pautar-se pela investigação da realidade, por uma prática intencional, de modo que as ações sejam marcadas por processos reflexivos entre os professores-formadores e os futuros professores, ao examinarem, questionarem e avaliarem criticamente o seu fazer, o seu pensar e a sua prática.
\end{abstract}

Com isso, faz-se necessária o desenvolvimento de um trabalho fundamentado num paradigma crítico e reflexivo que busque soluções para proceder intervenções na realidade escolar.

Segundo Alarcão (2001), assumir uma nova prática pedagógica é, hoje, o maior desafio dos professores. Ao longo dos anos o ofício do docente vem ganhando novos significados, novos pontos de vista e novos referentes de sua prática. Nessa perspectiva, o professor-investigador é consciente de que suas práticas pedagógicas não devem ser uma proposta sem reflexão do contexto em que está inserida. É imprescindível que haja reflexão sobre/na sua própria prática, transformando-a em um processo contínuo de ação-reflexão em que o professor percebe o seu fazer pedagógico como caminho para melhorar a sua prática docente e para a aprendizagem do aluno.

Nesse contexto, o estágio docente supervisionado pode ser compreendido como tempo de aprendizagem, como cita o Projeto Pedagógico do Curso Superior de Licenciatura em Letras-Espanhol do IFRN.

O estágio curricular supervisionado é entendido como tempo de aprendizagem, no qual o formando exerce in loco atividades específicas da sua área profissional sob a responsabilidade de um 
profissional já habilitado. O Parecer $n^{\circ}$ CNE/CP 28/2001 de 02/10/2008 destaca: O estágio supervisionado é um modo de capacitação em serviço e que só deve ocorrer em unidades escolares onde o estagiário assuma efetivamente o papel de professor. (PPC, 2012, p.26).

Trata-se, portando de um processo formativo de construção de identidade, tal como afirma Gauthier (1998), que o processo formativo de professores deve dar especial atenção para a construção da identidade profissional docente, para a definição dos saberes, das habilidades e de suas atitudes. A formação de professores deve ser integral, significativa e entendida como um processo pedagógico intencional (ZABALA, 1998). Consonante a isso, é necessária uma articulação entre ensino, pesquisa e extensão.

De acordo com Pimenta e Lima (2004), o estágio como espaço de investigação e pesquisa propicia, durante o processo formativo, possibilidades de compressão e de formação de professores-pesquisadores, críticos e reflexivos, capazes de analisar e refletir sobre/na sua prática docente por meio das experiências vivenciadas no ambiente educativo.

Para Barreiro e Gebran (2006) o estágio, que faz parte da formação inicial, deve ser um processo investigatório da realidade. Dessa forma, a prática docente necessita ser reflexiva e colaborativa, onde devem ocorrer pesquisas, questionamentos e avaliações constantes sobre as relações entre professor-aluno e sobre o fazer e o pensar docente.

Segundo Alarcão (2001), existem dois princípios básicos para que o docente seja um professor-investigador. O primeiro é que para ser verdadeiramente merecedor desse nome é preciso ter a investigação como uma atividade ligada à sua função. $\mathrm{O}$ segundo princípio é que formar para ser professor-investigador implica desenvolver competências para investigar na, sobre e para a ação educativa.

Refletindo sobre a utilização do Livro Didático (LD) no ensino, Luckesi (1994, p. 145) afirma que,

[...] o livro didático é um veículo de comunicação importante dentro do sistema de ensino; porém, não pode ser assumido acriticamente. Deve ser selecionado e utilizado de forma crítica, para que não sirva de veículo de conteúdos, métodos e modos de pensar que estejam em defasagem com a perspectiva que desejamos adotar.

Desse modo, cabe ao docente uma atenção no sentido de não permitir que o livro didático o substitua na escolha dos conteúdos nem na determinação das estratégias de 
ensino. Essa atenção deve ser redobrada quando da discussão dos conteúdos por ele veiculados. Pois, o conhecimento veiculado pelo livro não pode ser tomado como verdade absoluta, isenta de questionamentos, comparações, análises e contrapontos. (CARVALHO NETO, 2015)

Para Lopes (2007, p. 208) o livro didático é "uma versão didatizada do conhecimento para fins escolares e/ou com o propósito de formação de valores", diante disso, refletindo sobre o LD numa ótica pedagógica, pudemos perceber que a análise do livro didático deve ser feita de maneira crítico-reflexiva, a fim de contribuir para a ruptura do ensino reducionista e "articuladora dos interesses dominantes". Pois, segundo Saviani (2009, p.29):

Do ponto de vista prático, trata-se de retomar vigorosamente a luta contra a seletividade, a discriminação e o rebaixamento do ensino das camadas populares. Lutar contra a marginalidade por meio da escola significa engajar-se no esforço para garantir aos trabalhadores um ensino de melhor qualidade possível nas condições históricas atuais. $\mathrm{O}$ papel de uma teoria crítica da educação é dar substância concreta a essa bandeira de luta de modo a evitar que ela seja apropriada e articulada com os interesses dominantes.

Diante disso, percebemos que o LD não é apenas um recurso considerado como facilitador da aprendizagem e instrumento de apoio à prática pedagógica, mas também de cunho socioeconômico e político, em especial quando percebemos que esse é o único material impresso e sistematizado que circula dentre as camadas populares.

\section{Metodologia}

Para atingir nossos objetivos tivemos como aporte metodológico a abordagem qualitativa de investigação com foco na pesquisa documental e na pesquisa de campo. Para a pesquisa documental utilizamos as publicações elaboradas e disponibilizadas pelo Programa Nacional do Livro Didático (PNLD). Outra fonte de dados foi a coleção de livros didáticos - composta por três volumes - adotada pelo Ensino Médio Integrado do IFRN, campus Natal-Central (CNAT) no ano de 2016.

Em relação à pesquisa de campo, foram feitas entrevistas com três professoras de espanhol, colaboradores do estágio docente supervisionado. No que se refere à análise dos dados usamos a técnica de análise de conteúdo.

Considerando o tempo para o desenvolvimento das atividades do estágio II tivemos como sistematização de análise a divisão dos três volumes da coleção estudada. 
Cada um deles ficou sob a responsabilidade de três alunos, que durante os seminários de estágio socializavam o trabalho desenvolvido. Tal estratégia permitiu que o grupo classe se apropriasse do conhecimento de toda a coleção, tomando como princípio o trabalho colaborativo.

\section{Resultados e Discussão}

Segundo as Orientações Curriculares Nacionais (2006, p. 131) é preciso que ao se trabalhar com uma língua estrangeira no Ensino Médio levemos em consideração a interação com outras disciplinas. Assim, busquemos, sobretudo, "encontrar interdependências, e convergências, de modo a que se restabeleçam as ligações de nossa realidade complexa [...] precisa, enfim, ocupar um papel diferenciado na construção coletiva do conhecimento e na formação do cidadão".

A partir dessa perspectiva nos voltamos para a análise da coleção selecionada e elegemos dois aspectos orientadores para essa análise: as características físicas do material e o tratamento dado aos conteúdos da disciplina.

No que diz respeito às características físicas a coleção possui um livro impresso acompanhado de um CD com exercícios auditivos. Do nosso ponto de vista o livro impresso possui uma diagramação bastante atrativa, com cores e imagens convidativas a leitura. A coleção tem uma apresentação gráfica adequada as aprendizagens do espanhol no ensino médio e proporciona ao aluno compreender, por meio de suas ilustrações e textos a diversidade cultural das comunidades falantes do espanhol, além de contemplar diferentes gêneros discursivos com linguagem atualizada e propícia a faixa etária dos alunos. Ao utilizar imagens de pinturas clássicas e contemporâneas, oferece ao aluno a oportunidade de fazer a leitura dessas imagens, permitindo-lhe ampliar o conceito de leitura. Segundos as professoras entrevistadas o livro didático é "visualmente bom".

No que diz respeito ao $\mathrm{CD}$, esse é pouquíssimo utilizado pelos professores em sala de aula. Segundo os dados coletados nas entrevistas esse material "não agrada ao aluno". As músicas nele contidas estão "longe da sua realidade".

No tocante a apresentação dos conteúdos, poemas, anúncios publicitários, charges e outros elementos favorece o processo de ensino-aprendizagem. Os autores trabalham textos com linguagem contemporânea que possibilita a proximidade com os jovens. De acordo com a sua organização percebemos a preocupação com a aquisição das variáveis competências comunicativas: a expressão oral, a compreensão leitora, a 
expressão escrita e a compreensão auditiva.

Os autores trabalham com temas diversos e conseguem um equilíbrio quanto aos tipos de textos que utilizam. Ao mesmo tempo em que utilizam trechos de obras literárias, em poesia e prosa, articulam esses textos com o texto jornalístico, com a linguagem da internet, que se revela bastante atual e próxima da realidade dos alunos.

É visível a preocupação dos autores em envolverem os alunos na aprendizagem da língua espanhola, não resumindo apenas em aprender as estruturas gramaticais, mas possibilitando o contato e a valorização de outras culturas. O livro promove a imersão dos alunos no mundo hispânico, mostrando a imensidão de culturas, geografias, histórias, políticas sociais e identidades dos países que têm como língua oficial o espanhol.

As professoras entrevistadas destacaram como ponto positivo o foco no trabalho intercultural, sua maneira de tratar os diversos tipos de pronúncias do espanhol americano e o peninsular.

Observamos, ainda, que todas as unidades do livro analisado apresentam conteúdos gramaticais e textos de vários gêneros atualizados e de diferentes países hispano-falantes, sendo um ponto positivo para a educação integral dos alunos.

Entretanto, o espaço destinado à apresentação dos conteúdos gramaticais é muito resumido. Aspecto bastante ressaltado pelos professores entrevistados. Outro aspecto negativo destacado pelos professores se refere a pouca interação dos conteúdos apresentados pelo livro com os cursos técnicos integrados oferecidos pelo IFRN. Esse descompasso contribui com o fato dos professores não o utilizarem frequentemente. Esses preferem produzir seus próprios materiais didáticos para tratar dos temas específicos dos diversos cursos nos quais os alunos estão inseridos.

Outro ponto complicador para utilização da coleção estudada no IFRN é a própria estrutura curricular dos cursos técnicos integrados. De acordo com a sua organização o ensino do Espanhol como Língua Estrangeira (ELE) é concentrado no quarto ano do Ensino Médio Integrado ao Técnico, fazendo com que os professores tenham que trabalhar os três volumes da coleção em um mesmo ano.

Nesse sentido, percebemos a importância de um movimento de valorização do ensino da língua estrangeria no Ensino Médio, aqui em particular do ELE. Esse deve fazer parte de um currículo que possa, com um trabalho interdisciplinar, ultrapassar as necessidades profissionais e mercadológicas e contribuir com a formação integral do 
aluno. Nessa perspectiva, as Orientações Curriculares Nacionais para o Ensino Médio (2006, 147) afirmam que “dominar uma língua estrangeira supõe conhecer, também e principalmente, os valores e crenças presentes em diferentes grupos sociais", nos tornando seres conscientes do inacabamento e tolerantes com a diversidade.

\section{Conclusões}

Diante do estudo por nós realizado para a elaboração deste artigo, podemos perceber que o estágio é muito mais que um componente curricular, ele aproxima a realidade da atividade teórica, ou seja, é um elemento balizador para a prática docente a fim de romper com a dicotomia entre teoria e prática, pois o estágio como investigação é pautado na concepção de que "cada sala de aula é um laboratório e cada professor um membro da comunidade científica". (STENHOUSE, 1975, p. 142)

Nesse sentido percebemos que por meio da segunda etapa do estágio docente supervisionado de caráter investigatório foi possível ampliar olhares, assumir uma postura crítico-reflexiva acerca do ensino e do Livro Didático (LD). A análise do LD, orientada, é uma etapa balizadora para que haja reflexão sobre a prática docente e os conteúdos ensinados em sala de aula, além de nos possibilitar perceber o estágio como espaço de pesquisa para o processo formativo de professores de espanhol.

A prática reflexiva, considerada por nós como uma estratégia formativa no processo de estágio, propicia a ruptura entre a teoria e a prática, aproximando a realidade da teoria e possibilitando assim a construção da prática dialética.

Por fim, nossa pesquisa possibilitou fazer o diagnóstico de que o estágio docente supervisionado é imensamente indispensável na formação inicial do futuro professor, não somente porque há um embasamento teórico, mas porque, na medida em que são feitas as leituras com respeito a essa etapa pode-se perceber que não há um abismo entre a teoria e a prática, como pode ser comum se pensar. Ao contrário disso, a teoria deve estar sempre atrelada à prática docente.

Concluímos, então, afirmando ser de extrema relevância a etapa teóricoanalítica, presente na proposta de estágio docente do IFRN. Tal proposta nos proporciona o conhecimento do material didático e esse esforço prepara uma série de reflexões não só relativas ao livro didático, mas sobre tudo, relativas à importância do professor elaborar o seu próprio material didático, formado pelo conjunto de recursos de que dispõe. 
Por conseguinte, tais reflexões nos fizeram chegar à conclusão de que o LD é um elemento de fundamental importância para o desenvolvimento do trabalho docente, no entanto, deve ser percebido como um ponto de referência, não devendo ser encarado como o único material a ser utilizado em sala de aula. É fundamental saber que o uso do LD não elimina a possibilidade de novos recursos e sim auxilia na seleção e organização dos objetivos e conteúdos escolares.

\section{Referências}

ALARCÃO, Isabel. Professor-investigador: Que sentido? Que formação? 2001.

BARREIRO, I. M. F; GEBRAN, R. A. Prática de ensino: elemento articulador da formação do professor. São Paulo: Avercamp, 2006.

BRASIL. Guia de livros didáticos: PNLD 2015: língua estrangeira moderna: Ensino Médio. Brasília: Ministério da Educação, Secretaria de Educação Básica, 2014.

Lei 9.394 de 1996. Lei de Diretrizes e Bases da Educação Nacional. Brasília/DF, 2006.

BRASIL, Ministério da Educação, Secretaria de Educação Básica. Orientações Curriculares para o Ensino Médio; vol. 1: Linguagens, códigos e suas tecnologias. Conhecimento de línguas estrangeiras. Brasília: MEC, 2006.

CARVALHO NETO, E. R. G. O livro didático e as teorias pedagógicas. Holos 6 , 2015.

GAUTHIER, Clermont (et. al), Tradução Francisco Pereira. Por uma teoria da pedagogia: pesquisas contemporâneas sobre o saber docente. Coleção Fronteiras da Educação. Ijui: Ed. UNIJUÍ, 1998.

INSTITUTO FEDERAL DO RIO GRANDE DO NORTE (IFRN). Projeto Pedagógico do Curso Superior de Licenciatura em Letras-Espanhol do IFRN. Disponível em <http://www.ifrn.edu.br/>. Natal/RN: IFRN, 2014.

LIBÂNEO, José Carlos (1994). Didática. São Paulo: Cortez. p. 15 -29.

LOPES, Alice Casimiro. Currículo e Epistemologia. Ijuí: Editora Unijuí, 2007, p. 205-228.

LUCKESI, Cipriano Carlos. Filosofia da educação. São Paulo: Cortez, 1994.

PIMENTA, Selma Garrido (2001). O estágio na formação de professores: unidade teoria e prática? 4. ed. São Paulo, SP: Cortez.

PIMENTA, Selma Garrido, LIMA, Maria Socorro Lucena. Estágio: diferentes concepções. In: Estágio e Docência. Ed. Cortez. SP 2004, p 33- 37. 
SAVIANI, Dermeval. Escola e democracia. Campinas, SP: Autores Associados, 2009.

STENHOUSE, L. (1975). Na introduction to curriculum research and development. London: Heinemann.

TARDIF, Maurice. Saberes docentes e formação profissional. $2^{a}$ edição. Petrópolis: Vozes, 2002.

ZABALA, A. A prática educativa: como ensinar. Tradução de Ernani F. da Rosa. Porto Alegre: Artes Médicas, 1998. 